\title{
SWOT Analysis Of Patent Information Service Strategy Of University Libraries For Enterprises
}

\author{
Pengfei Ji, Xiaozhu Zou, Zhi Li \\ Institute of Science and Technology Information (Nanjing University of Aeronautics \& Astronautics), Nanjing \\ 211106, China
}

Keywords: enterprises; university libraries; patent information; swot analysis

\begin{abstract}
In recent years, university libraries have stepped out of the campus and began to focus on scientific research departments. University library information resources, the use of specialized subject in the premise of service for teaching and research, from the collection of information to the network information, efficient collection of information, the source of the whole sequence and processing, the time and space constraints actively cooperate with local enterprises to provide information services. According to the domestic situation, a detailed analysis of the University Library as the information service department in the patent information service on the internal advantages and weaknesses, external opportunities and threats, and put forward the WT strategy as the dominant strategy, with the implementation of SO strategy, WO strategy and ST strategy countermeasures.
\end{abstract}

\section{INTRODUCTION}

The university library is the document information service center of the University, it is the biggest technical prop of teaching and scientific research work, and is the most comprehensive information resource distribution center. At present, the information service consultation work of university library is limited to the teaching and scientific research of the university.

Patent information has become the most important strategic resource in the era of knowledge economy. On the one hand, the enterprise needs the patent information service and the University's patent achievement, on the other hand, the university library has the characteristic collection and the rich patent information resources can not be used for the development of the enterprise. The enterprise to find solutions, this is a waste of resources, which not only restricts the development of enterprises, but also to improve the level of University Library lost opportunities in a wide range of services. With the advent of the digital age, advanced information technology tools for the university library information service has brought great convenience, users can easily enjoy lending, query and other services. However, with the diversification of the service means and service contents, university libraries are facing unprecedented pressure. With the emergence of a large number of information institutions and web search engines, university libraries are no longer the only choice for information acquisition in Colleges and universities. Therefore, in the face of the change of the environment and the fierce market competition, the university library should seize the opportunity of the patent information service and accept the challenge. Therefore, at the same time in the University Library Based on the basis of the work, we should give full play to the three functions of teaching, scientific research and social service, passive service, take effective way, promote their own characteristics and advantages to enterprises, and gradually establish a good cooperation mechanism of enterprises, in-depth understanding of enterprise, master of business needs, provide timely the patent information required for the enterprise, enhance the market competitiveness of enterprises. At the same time, the university library occupies its own position in the patent information service market, in order to survive and develop.

\section{FEASIBILITY ANALYSIS -SWOT ANALYSIS}

\subsection{Internal Advantage}

Figure 1 is the advantage of the University Library as the information service department in the patent information service, including the following aspects:

(1) Resource advantage. The university library has abundant literature information, in addition to the paper version of the literature, database and other electronic and cyber source, continuity and integrity of the information is not compared to other information institutions, these rich collection resources provides literature resources guarantee for patent information service.

(2) Personnel advantage. University libraries, the library is usually comprehensive professional knowledge and other disciplines of professional knowledge, have good ability to obtain information, the level of foreign language and computer network operating skills for information query, processing and finishing than other experienced personnel. The librarian can make full use of the library and the library network information collection, information concerning patent service enterprises, customized for the project, according to the changing environmental regulation service content, through the quantitative analysis method to provide targeted, in-depth research services, to provide support for decision making. 
(3) Equipment advantage. Based on the school's emphasis on the modern technology, the investment of the university library to the database is relatively large, and there are enough funds to support and the technical guarantee of the equipment.

(4) Environmental advantages. The University Library in the university scientific research environment, University experts and scientific research personnel and the professional teachers have a clear understanding of related technology and local level, can provide help for the relative authority of the library patent information service, deep processing and conducive to the development of the patent information, making higher utilization rate information products. In addition, the University Library and scientific research institutes will be related to the cooperation, but also to provide convenient conditions for literature sharing.

(5) Process method. The process of information service of university library is more rigorous, and the corresponding norms, and more professional, to provide a good foundation for the flow of high energy knowledge.

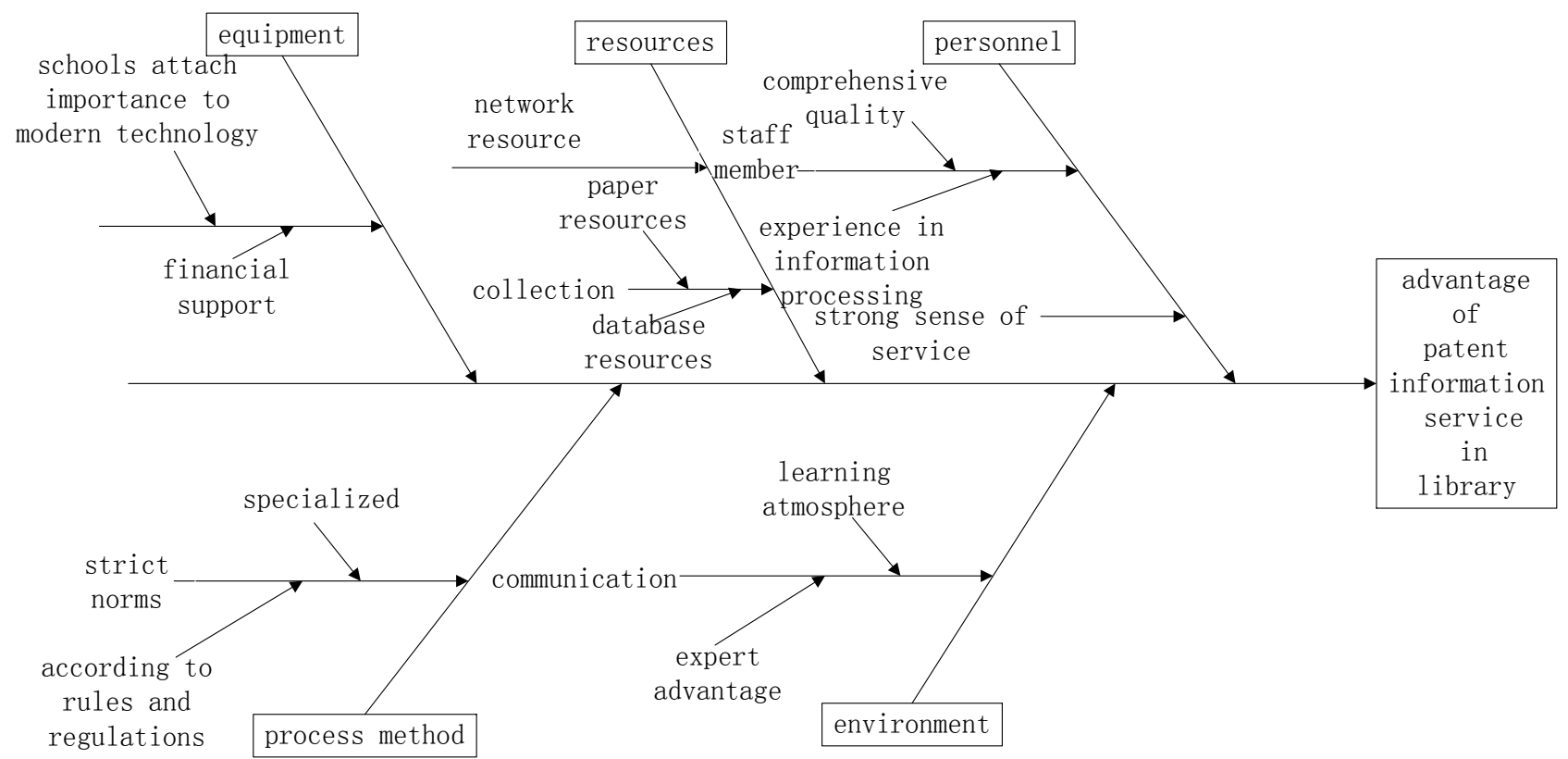

Figure 1: Advantages of university patent information service.

\subsection{Internal Weaknesses}

Only the most simple and most patent information service of university library, which provides the patent information website for the reader to find free patent information, only a small part of the library two times finishing and deep development and utilization of free patent resources.

(1) University intellectual property management is not enough attention. The current university patent transformation exists, there is no lack of quantity quality conversion efficiency and lack of platform integration issues, the fundamental reason lies in the lack of knowledge, financial support is not enough, the market consciousness is not strong, the platform is not perfect. The patent policy of colleges and universities is not matched, the mechanism of benefit distribution is unreasonable, the lack of necessary supervision and evaluation mechanism. The Patent Administration Department of the university is separated from the patent technology transfer department and is responsible for the management of different departments. This kind of management mode leads to the scientific research managers pay more attention to the patent application and management, while ignoring the patent technology transformation. Staff do not understand the patent management, it is difficult to understand the details of the patent technology, to a certain extent, affected the transformation of patent technology $y^{[1]}$.

(2) Patent information service vacancy. At present, attaches great importance to patent information service did not cause the library, all colleges and Universities between the uneven development and consulting staff of University Library initiative to grasp the lack of market awareness, most users just wait for the door, take the initiative to provide the service is also very difficult to obtain the approval of personnel research group.

(3) Lack of patent information services. Patent information relates to technology, economy, law, foreign language, science and engineering background, computer technology, library and information related knowledge. Although the comprehensive ability of university librarians is strong, but the lack of professional training system, the patent information retrieval and patent intelligence analysis is relatively small compared to the scientific and technological novelty search, the problem of the fixed Title service. Lack of patent information talent, the actual content of the patent service is less, not the formation of scale, professional service model, did not take the initiative to grasp the market information feedback statistics, lack of competitive awareness. 


\subsection{External Opportunity}

In 2008, the State Council officially issued the "outline of the national intellectual property strategy, reflects the country attaches great importance to intellectual property rights; the State Council in October 2014," a number of opinions "on accelerating the development of technology services in the clear requirements to develop intellectual property agency, law, information, consulting, training and other services", "to mobilize University and scientific research institutes, enterprises and other types of talent in science and technology services in the field of innovation and entrepreneurial enthusiasm"; in March 2015, the CPC Central Committee and State Council issued "on deepening the reform of institutional mechanisms to accelerate a number of opinions" pointed out that the implementation of innovation driven development strategy, the establishment of institutions of higher learning and scientific research institutes of technology transfer mechanism "," strengthening the management of higher education and scientific research institute the intellectual property rights". Thus, in the innovation and entrepreneurship popular tide, countries for intellectual property rights and pay attention to, pointed out the direction of innovation driven ${ }^{[2,3]}$.

\subsection{External Threats}

(1) Governments at all levels to build a public welfare patent information service platform. At home, the national and provincial and municipal areas of patent management agencies are mainly composed of the Intellectual Property Office, the science and Technology Bureau and other government departments. These government departments give full play to the patent management functions for patent practitioners, patent administrative organs, enterprises and patent inventors, patent management, patent information resources construction, patent information services, education and training work. The patent management and service of the government has the characteristics of unity, standardization, authority and specialty. In today's information and network era, the intellectual property bureaus at all levels of government as the main representative of the patent management and service department, have the effort to build a professional website, carry out a comprehensive online patent service. According to the survey, in addition to Tibet, the rest of the 30 provinces and autonomous regions have built a patent information management and service network. The government by building these convenient, fast and efficient patent information service platform, issued patent statistics, patent policy and other information in a timely manner, providing patent information resources and services for free, convenient for the public, so as to improve the patent daily management work efficiency and service quality. According to the survey, the patent information service provided by the website of the intellectual property office at the provincial level includes: patent resource service, patent administration service, patent value added service and so on.
(2) Rapid development of commercial patent information service. The commercial patent information service refers to the patent information service provided by the patent agencies, law firms, patent information technology service providers and consulting companies. Commercial patent information services for the purpose of profit, mainly to provide patent search, patent analysis, patent rights, patent data, patent software and other professional and in-depth services. The following is a case study of patent agencies, law firms and patent information companies to conduct business information services. According to the State Intellectual Property Office statistics, China's domestic patent agency (Patent Office) a total of 870, widely distributed in all parts of the country, where the largest number of Beijing, a total of $231^{[4]}$.

Research found that the patent agency is a basic service providing patent business, is one of the main contents of the commercial patent information services including: patent application, invalid, review, administrative litigation, tort litigation and tort administrative investigation; basic patent retrieval, especially patent information retrieval, topic retrieval and the legal status of retrieval, patent retrieval, competitor retrieval, retrieval, import and export of invalid patent search, patent infringement, patent retrieval transaction information retrieval, foreign patent retrieval environment. At the same time to provide basic services, some of the strength of the comprehensive patent agency in accordance with the needs of customers, the use of its human resources, the development of a competitive feature services. Some special service for large enterprises, overseas service, small and medium enterprises; some research patent platform, patent analysis tools and other information products; some develop patent information consulting services, patent consulting etc.

\section{COUNTERMEASURE AND MEASURE}

According to the principle of complementarity and weaknesses, strategic choice of favorable conditions to make full use of external opportunities and internal, and avoid external threats and internal shortcomings, so there are four different strategies: SO strategy, WO strategy, ST strategy and WT strategy, as shown in figure 2. 


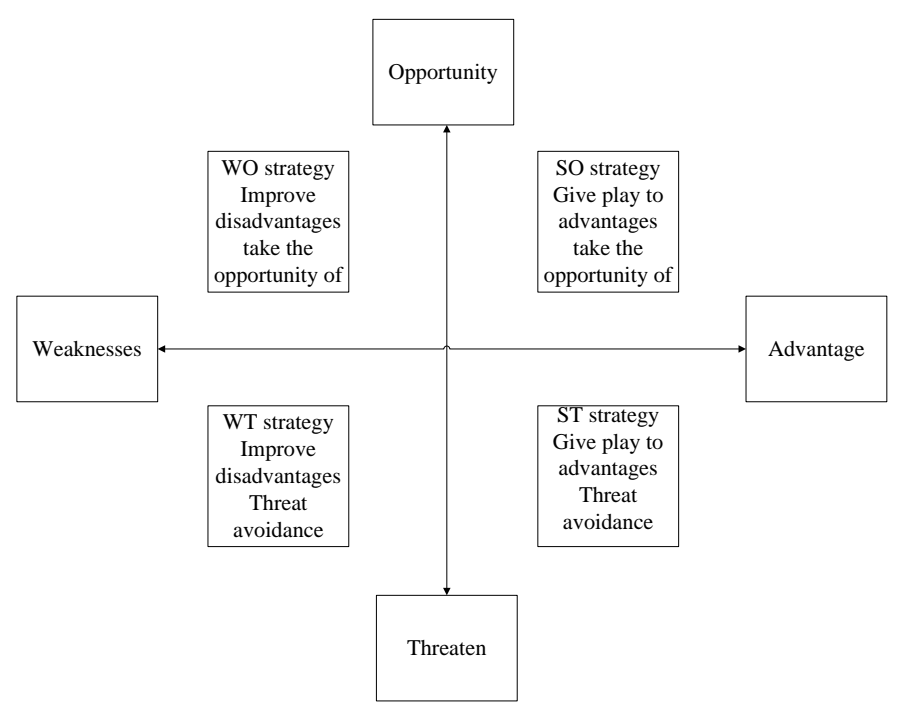

Figure 2: Schematic diagram of countermeasure strategy based on analysis.

\subsection{SO Strategies}

(1) Integration of existing resources. Relying on the government's policies and funds and other social capital, the establishment of characteristic patent database, the establishment of a reasonable distribution, efficient and reliable patent information resources system. And small and medium-sized enterprises as well as scientific and technological intermediary to carry out joint cataloging, build a joint catalog database. The digitization of the collection of documents and the advantages of resources are the basis for the construction of the national patent information service network of University Libraries and the formation of a virtuous circle of interactive development of National University libraries. Make full use of the network platform to carry out patent services, each library timely release of the museum information, provide online booking, literature and reference services ${ }^{[5]}$.

(2) Carry out a variety of promotional activities. Patent information resources belong to the information product, because a lot of information products only when readers use and experience to know its value, so the library can be more people into the museum time, patent information service propaganda library, provide free browsing and trial patent database opportunities for the reader. Let the reader understand the huge information resources, provide training and guidance to help them master the methods and ways to find and use information. Regularly hold the patent achievement information conference, set up patent knowledge training class, attract potential patent information service users, and enhance their trust in the Library Patent Information service. In the network promotion, can highlight the content of library image, unique resources, service means, the establishment of virtual library, readers through the network of Library Services Library timely feedback to help understand the needs of readers, improve the service and timely adjust the allocation of resources and resource construction.
(3) Increase the degree of opening to the society to adapt to the local economic development. In addition to the library information service of the university patent, should further open to the community, to serve the local economic construction as the basic conditions for the local science and technology workers to improve the information needs of patent information service. Through marriage with the local government and enterprises, the implementation of joint library, make full use of the funds from all walks of life support, strengthen the necessary patent documents and patent information construction, to create convenient conditions for sharing of library resources and the user. A new approach to the construction of local economy by exploring the win-win situation between University Library and local.

\subsection{WO Strategies}

(1) Establishing patent information management system. Because most of the protection of intellectual property rights and management is the responsibility of the Department of science and technology, patent patent database by the library, to provide training for personnel responsible for the patent, archives by the archives, but the lack of communication and coordination between departments. Lack of information research and patent application, the lack of information service of the library. Therefore, it is necessary to establish a set of effective patent management system, which is responsible for the management and coordination of the patent information service in Colleges and universities.

(2) Improve the quality and ability of librarians. Librarians' quality and ability of university library is the fundamental guarantee for the success of patent information service, the rapid development in science and technology today, the library staff patent information service faces learn new knowledge and master new skills challenge, so the library should establish a perfect mechanism of education and training. On the one hand, through on-the-job training, job training and other ways to promote the Librarians' knowledge, skills development, update potential mining, open field of vision; on the other hand can set up a patent information service jobs, training librarians become part of patent service commissioner, is mainly responsible for the patent information retrieval services, assist researchers to obtain the latest patent information.

\subsection{ST Strategies}

(1) Establish patent database.To carry out the patent information service is the extension of the existing content of university library, and it is also an effective way to make full use of the resources and improve the service ability. To better carry out the patent information service, it is necessary to have a proprietary database. The patent characteristic database refers to the collection and collation of the patent information resources in a certain subject or field, which is comprehensive and systematic. The development of information resources of university library should be based on the school, the social focus, play their 
own advantages, increase the breadth and depth of information resources and library development, scientific analysis and processing on the first hand data, making it a high quality required by enterprises and the society, the quality of information.

(2) Library cooperating with patent agency to serve enterprises. The library can open access related resources to the patent agency, can serve as a bridge between enterprises and patent agencies, patent agencies recommend a good reputation to help enterprises and enterprises patent agencies; patent agencies to provide special places as the office of enterprise patent services, and generation of patent agencies receiving enterprise application, complete information of demand submit the enterprise, both for the convenience of enterprises, also improve the efficiency of the service for the patent agency.

\subsection{WT Strategies}

(1) Improving the consciousness of patent information service in Colleges and Universities. The consciousness of patent information service of University Librarians refers to the sensitivity to the information service and the strength of the service consciousness, which plays a decisive role in the final behavior and directly affects the effect of the behavior. For a long time, many university library information staff actively grasp the market awareness is not strong, still remain in the waiting, waiting for user home project stage. And due to the lack of estimates of various factors in the market, often resulting in a lot of manpower and material resources to develop information products have little effect.

(2) Increase investment, improve the patent information service rules and regulations. The problem of funds is the key problem of extending patent information service. Any modern patent information service platform construction, need to invest considerable funds. The purchase of resources, the employment of personnel, the development of technology, the maintenance of equipment, etc., need great investment. The construction of public welfare patent information service platform, the need for adequate operating funds. The establishment of an effective patent information service system and service standards, including the search criteria, fees, professional skills, etc., the library patent information services into scientific and standardized management track.

(3) Patent institutions to train professionals in libraries. The university library should not only rely on the enterprise retired experts, industry consultants, patent agencies, but also pay attention to train a number of patent information service personnel. In addition to attend various training courses, the library can also through the patent agency Bangdai on library personnel training, can appoint personnel to the patent office practice, including writing, the patent application documents of patent search, patent consulting skills will help the library to provide enterprises with patent information service better.
(4) Service should be novel and authoritative. Find and compare service is not limited to domestic patent, pay more attention to the progress of foreign patent, not limited to the search for a patent with patent novelty, we must pay more attention to the development trend of the industry, such as development of patent early warning analysis report, provide patent technology tracking services, only this kind of high the technical content of patent information in order to arouse the concern of enterprises, to bring real benefits to the enterprise, help the enterprise to win the patent war in the fierce competition in the market. Patent information not only for enterprises to solve the present problem, but also to provide reference for the future development direction of decision, so we must have the authority, patent information service personnel to search, based on the integration of various resources, the use of a variety of patent analysis tool for the enterprise to provide authoritative and accurate information.

The above analysis of the development of patent information service in University Libraries in China's comprehensive results can be seen: China's University Library and its advantages and disadvantages coexist, the external opportunities and threats, but overall, a greater threat than opportunity, advantage is less than disadvantages. The advantages of University Library in the field of patent information service is not enough to constitute the ability to capture the greatest opportunity, and taking into account the ability of innovation is the power source of an enterprise development and occupy the dominant position, which is currently in the development of enterprises in China are lacking, so should give priority to the development of University Library patent strategy as the key WT information service strategy, emphasizing the "strength" of the practice, the integrated use of various means to improve their service capabilities, improved has its own developing disadvantage and try to seize external opportunities to give. At the same time, in order to implement a full range of overall development strategy, but also with the implementation of SO strategy, WO strategy and ST strategy.

\section{Conclusions}

In this paper, we firstly analyzes the necessity of University Library Patent information service, and then makes a SWOT analysis on the feasible model, a detailed analysis of the University Library's internal advantages and weaknesses, external opportunities and threats, and put forward the WT strategy as the dominant strategy, with the implementation of SO strategy, WO strategy and ST strategy countermeasures measures.

\section{REFERENCES}

[1] Bing Liu, Tingting Xie, and Ju Lai, "Research on The Problems and Countermeasures of Patent Transformation in Colleges and Universities", Chinese University Science and Technology, 8, pp. 50-51, (2015). 
[2] Feng J, Zhao N. Zhang, "A New Role of Chinese Academic Librarians-The Development of Embedded Patent Information Services at Nanjing Technology University Library, China", Journal of Academic Librarianship, 3, pp. 292-300, (2015).

[3] Jiadong Han, "Innovation Path of Small and Medium Sized Enterprises", Enterprise Reform and Management, 4, pp. 81-82, (2008).

[4] Chunhong $\mathrm{Wu}$, "To Investigate The Photoengraved Western Language Books Research and Cataloging", Science and Technology Information Development and Economy, 1, pp. 55-57, (2010).

[5] Brewer, Bailey. "Making It in the Academic World", American Libraries, 9, pp. 20-21, (2015). 